\title{
Application of Watershed Analysis in Flood and Erosion Control using GIS and Remote Sensing
}

\author{
Ahmed Mohammed ${ }^{1}$, Ezra Enoch Alhamdu ${ }^{1}$ and Ibrahim Muhammed ${ }^{1}$ \\ ${ }^{I}$ Department of Surveying and Geo-informatics, School of Environmental Sciences, Modibbo \\ Adama University of Technology, PMB 2076 Yola, Adamawa State, Nigeria
}

\begin{abstract}
This paper focuses on flood-prone unplanned built-up areas to determine suitable drainage network. A comprehensive method of data collection involving topographic maps produced from aerial photography, satellite image and Total Station were employed. Three-dimensional (3D) coordinates were collected using Total Station and these were used to produce a Digital Elevation Model (DEM) and its contingents, comprising Watersheds, Aspects and Slopes to obtain suitable drainage sites. Two results were obtained, the Optimal Drainage Network $(O D N)$ and the Suitable Drainage Network (SDN). The former however, has advantage for future and sustainable development in the area over the later. However, SDN is cheaper when it comes to compensation of demolished buildings during drainage construction. Results suggest that a combination of surveying equipment, aerial photogrammetry and satellite images can provide ideal solutions to environmental problems.
\end{abstract}

Keywords: Flood, DEM, Watershed, GIS, Remote Sensing

\section{INTRODUCTION}

The factors that bring about land degradation are numerous, and that include flooding, desertification, erosion, fire hazards etc. Flooding is particularly important considering surface damage it does to the land. In the developing countries, the problems of flooding have been on the increase.

Floods occur due to various reasons depending on the relief, climate, vegetation cover, soil and geology of an area. This includes surface runoff influenced by the nature of the soil. Drainage basins with impervious soils lead to flood because the water is hardly absorbed. The relationship between sub-surface geology and flood investigated by Charley (1989) shows that flow of water is related to geological structure of an area. The knowledge of geology is prerequisite to a thorough comprehension of flood. He further argued that, basement rocks mainly constituted by pre-Cambrian rocks that are crystalline do not allow infiltration.

Excess rainfall due to anomalous climatological effects also cause flood. When there is a heavy downpour within a short period of time resulting in rainfall excess, existing drainage capacity could not adequately take it, leading to a stagnation of surface runoff for some period leading to flooding (Ward, 1978). In the developing world, poor planning and inadequate drainage systems are the main causes. In this case human interference is viewed in the context of urbanization resulting in a new physical landscape and a new ecosystem (Akintola, 1978). Tides also cause flooding and inundate coastal areas when not enough wave breaks are built. In addition, tsunamis can also cause an unprecedented overflow of water at the coastal areas leading to serious damage.

With the advancement in Global Positioning Systems (GPS) and software tools such as the Geographic Information Systems (GIS), it is possible to map out areas liable to flood and delineate drainage patterns. This will provide the opportunity to manage flood since it cannot be avoided in totality.

These processes involved making use of remotely sensed images, GIS and Total Station 3D coordinates to provide Digital Elevation Model (DEM). Watershed is then produced from the DEM and analyzed to produce a drainage network. While DEM represents a 3D model comprising longitude, latitude and the third dimension being temperature, pressure, height etc. Here, the third dimension is height. Generally, geographically represented DEMs constitute numerical description of the surface of the terrain based on the measured or derived coordinates of numerous scattered ground points.

Watersheds are hydrological drainage basins, land areas, which catch rain or snow and drains to a specific marshes, streams, lakes or ground water aquifers (Musa, 2001). Traditionally watershed boundaries are drawn manually on to a topographic map. The analyst then uses topographic features on the map to determine where a divide is located. Today, computer programs are widely used to derive watershed from DEM. Using computer technology we can generate preliminary watershed boundaries in just a fraction of time.

Since watersheds are areas that drain surface water to a common outlet (e.g. streams, rivers, marshes etc), then the delineation of watershed can take place at different spatial scales. A large watershed may cover an entire stream system and within the watershed system, there may be smaller watersheds, one for each tributary in the system. Hence, there is the need to explore new approaches in solving these peculiar flood problems by employing watershed analysis through the use of remote sensing and GIS. One greater advantage of this is the 
ability to use GIS, which is a set of computerized tools for the digital data processing, analysis, storage, retrieval, and display of geographically referenced spatial information together with their attributes (Musa, 2001). The essential features of a GIS, in addition is the ability to create a temporal and spatial databases and to manage and analyze them at will (Ndukwe, 2001).

Watershed analysis provides the process of formulation and carrying out of a course of action involving modification of the natural system of watershed to achieve specified objectives. This can be integrated into a GIS environment for better and faster results.

The study area is Sangere, a small town in Girei Local Government Area of Adamawa State, Nigeria. The town experiences environmental degradation due to perennial erosion arising from improper drainage system. The present drainage pattern occurred naturally, and the once plain agricultural field is now fully habited with unplanned layouts. This research aims at selecting suitable drainage networks using state-of-the-art technology so as to minimize the effects of flood hazard through the use of watershed analysis.

\section{METHODOLOGY}

Two instruments have been used that include Total Station (SOUTH Inc) and Handheld Garmin 60 GPS Receiver, and three software packages that include Integrated Land and Water Information System (ILWIS) version 3.1 and 3.3 Academic, CorelDRAW suite 12 and AutoCAD version 2010.

The procedure involves first, scanning of topographical map of the area having a scale of 1:50,000 and contour intervals of 50ft. Points are established along contour lines that crosses the study, from which the traversing was commenced. In addition, satellite image from Google Earth ${ }^{\mathrm{TM}}$ with a spatial resolution of $60 \mathrm{~cm}$ was obtained (Figure 1a), and this is used for digitizing the current geometry of physical features, especially the built-up areas within the case study area. These two serves as base maps.

The coordinates of the two points to be served as the Control Points for Eastings, Nothings and Heights were interpolated from the topographic map, and were then set out on to the ground using a hand held GPS. The Total Station was then fully oriented to make sure no collimation errors occur during field measurements. After this, spatial data capture commenced whereby Eastings, Northings and Heights of scattered points were taken. Other details taken include existing drainages within the boundary of the study area.

Due to the fact that AutoCAD is strong in terms of vector data processing, making it the Master of COGO (Coordinate Geometry), the horizontal geometry of the acquired spatial data using Total Station was plotted in AutoCAD 2010 Version. Details plotted include points from which the contour lines were generated where by the height values were inputted when the drawing was exported in to ILWIS software. Other details plotted include the existing drainage within the case study area.

\subsection{Creation of Digital Elevation Model}

The DEM was generated by ordinary Kridging method in ILWIS (Figure 1b), with a precession of $0.001 \mathrm{~m}$. The choice of this technique is based on the fact that it gives precise DEM when the study area is very small. In addition, it is a standard procedure in many GIS software packages, including ILWIS 3.1, Surfer 8, and TNT-MIPS (Kumura, N, 2008).

\subsection{Creation of Watershed Map}

The watershed map is produced (Figure 1c). It refers to Flow Accumulation and it gives a cumulative count of the number of pixels that naturally drain into outlets. The operation can be used to find the drainage pattern of a terrain. As input, the operation uses the output map of the Flow direction operation. The output map contains cumulative hydrologic flow values that represent the number of input pixels that contribute any water to any outlet (or sinks if these have not been removed). The outlets of the largest streams, rivers et cetera will have the largest values. However, the watershed has other characteristics that need to be studied, that include gradient and steepness represented by Slope Map and flow direction represented by Aspect Map. They are created by the use of separate raster objects for each of these terrain characteristics in ILWIS.

\subsection{Creation of Slope Map}

Slope is the first derivative of altitude on the terrain surface. It shows the rate of change in height of the terrain over distance.

To calculate slope maps in percentages and in degrees, equation 1 is used.

$$
=\operatorname{rad} 2 \operatorname{deg}\left[\arctan \left(H * \frac{L}{A}\right)\right]
$$

where $\alpha=$ Slope, $\Delta H=$ Contour Interval, $\Sigma L=$ total length of contours in the area, and $A$ is the size of the area. 

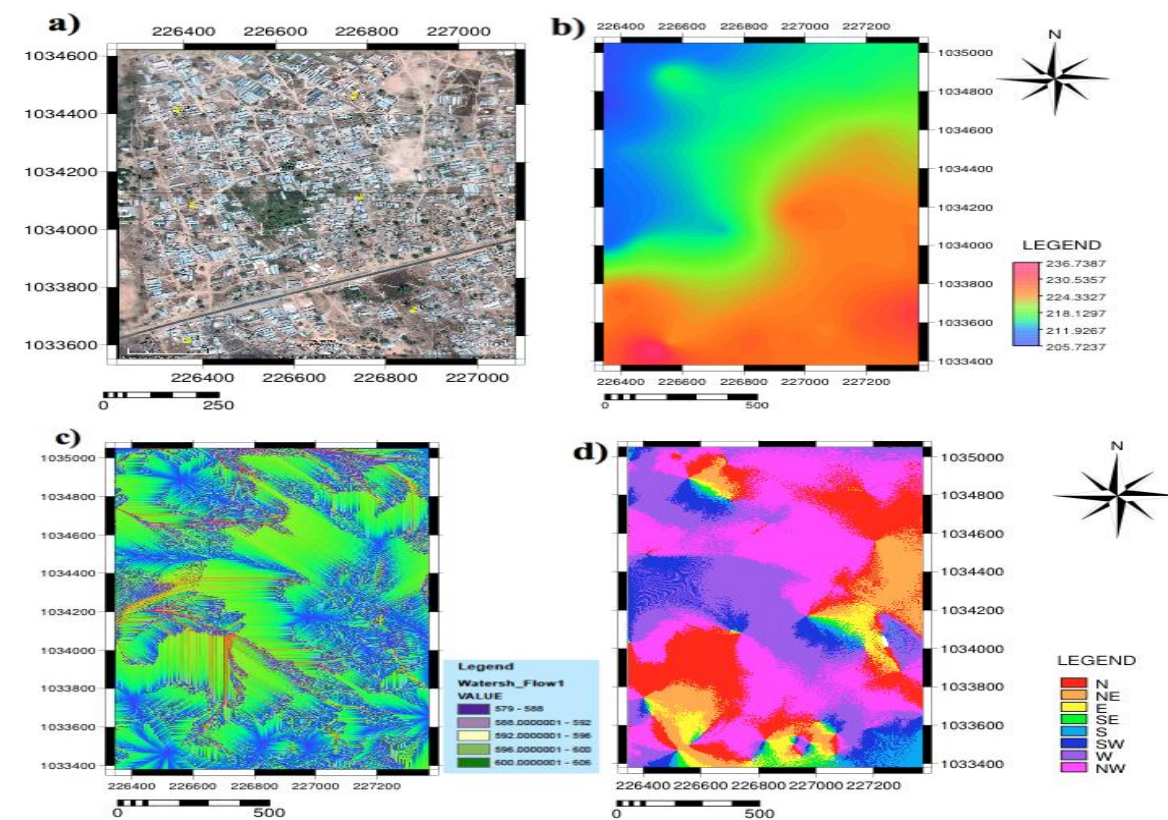

Figure 1: Maps of the study area showing a) Aerial view from satellite image, Courtesy: Google Earth ${ }^{\mathrm{TM}}$, b) Digital Elevation Model, c) Watershed map, and d) Aspect map.

\subsection{Creation of Aspect Map}

The term aspect is defined as the direction of the biggest slope vector on the tangent plane projected onto the horizontal plane. Aspect is the bearing (or azimuth) of the slope direction, and its angle ranges from 0 to $360^{\circ}$ ( $\mathrm{Li}$ et al, 2004). Aspect is computed from the directional slopes obtained. This is computed as in equation 2 .

$$
=\operatorname{rad} 2 \mathrm{deg} \arctan \frac{\text { Col }}{\text { Row }} \div
$$

\section{Results And Discussions}

The built-up areas were first digitized from the satellite image shown in figure 1a. The built-up map is used in this project during overlay operations in order to use the road networks in between the built-up areas to serve as a surrogate for the suitable drainage networking.

The DEM (Figure 1b) shows higher grounds to the south and lower to the northwest region. This explains the general background on the direction of flow at any point in time. However, DEMs are mostly homogenous even if the scattered data points are many as in this case, hence provide less of finer details on the direction of flow. This has prompted the need to build a watershed map to show where water can easily be drained to during flood.

The watershed map shows possible areas of drain to the northwest. This realistically explains the physical attribute of the area, with areas mostly affected by flood concentrating to the northwest.

The direction of flow shown by Aspect Map (figure 1d, and key) shows interesting results. The flow is dominated by northwest (pink) and west (purple). Even though flows in other directions are also significant, they tend to add to the NW flow, for example northward flow. It is important therefore to observe the slope of the study area. The slope perhaps is the most important aspect of surface form, since surfaces may be formed completely form slope angles. Slope is the first derivative of altitude on the terrain surface. Here, it shows the rate of change in height of the terrain over distance. Most significant regions are southwest, and other lesser ones spread between central and northwest (Figure 2a). Even though these show good results to be reckoned with, we go further to establish viable computations that can help achieve our goal of determining drainage pattern. We try to work out different alternatives of drainage we can achieve.

This further analysis resulted in to two alternative Drainage Networks, first the Suitable Drainage Network (Figure 2b) that will avoid demolition of buildings by using Road Network as surrogate. Second, the Optimal Drainage Network (Figure 2c) which require demolition of some buildings but will yield the most probable solution to the hydrological problems akin to erosion and flooding than the Suitable Drainage Network. 
Whichever network chosen, however, the width of the drainages to the southern part of the area should not be less than $2 \mathrm{~m}$, and $2.5 \mathrm{~m}$ for the drainages in the northern part considering the effect of Flow Accumulation as shown previously from the watershed map (figure 1c).
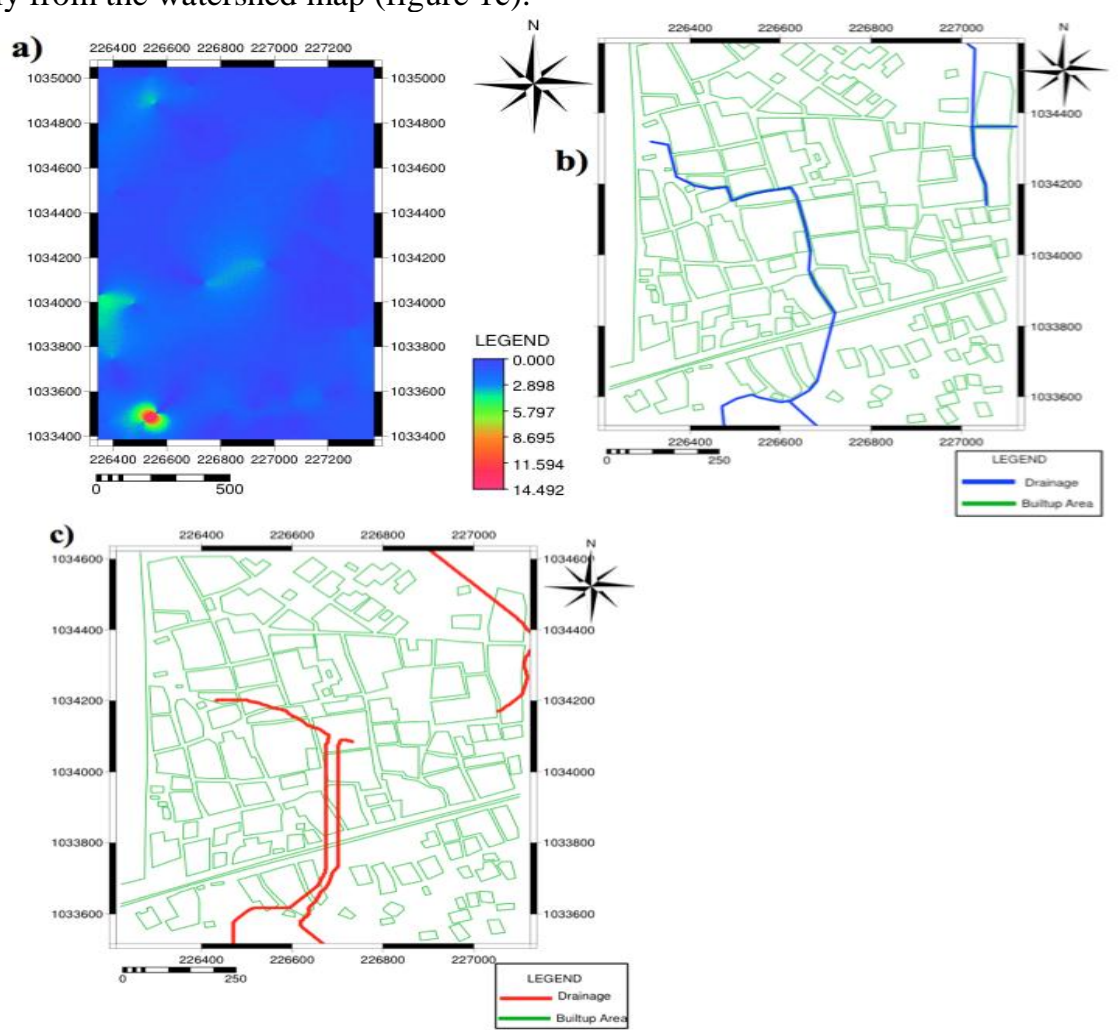

Figure 2: Maps of the study area showing a) Slope Map, b) Overlay of Suitable Drainage Network (SDN) on Built-up Area, c) Overlay of Optimal Drainage Network (ODN) on Built-up Area. The built-up areas where obtained after digitizing the satellite image in figure 1a.

\section{Conclusions And Recommendations}

This paper investigates practicable solutions to flood and erosion problems affecting Sangere town using modern surveying equipment. Various stages of data collection and processing were involved leading to the production of a DEM and its contingents such as watershed, Aspects and Slopes. The output shows that a combination of land surveying, topographic maps produced by aerial photography and remotely sensed images from satellites can be combined to solve terrestrial problems even on a small region of six hectares. This is possible due to the fact that Total Station gives better accuracy than any other instrument when it comes to obtaining 3D surface coordinates.

Two result options were achieved and these can be implemented depending on the interest of government that passes policy. The first is the Suitable Drainage Network, whereby government will not demolish any structure during the process of establishing such drainages. As a matter of fact, building substandard drainages will suffice without having to demolish and compensate house owners. The second is the Optimal Drainage Network, and this takes into consideration of future developments of the area, so standard drainages have to be built-up. But note the caveat about the relevance of this method. The government stands a chance of paying displaced persons on demolished properties.

\section{References}

[1] Akintola, F. O. (1978). Hydrological consequences of urbanization. A case study of Ibadan city. Page 151.

[2] Charley, R. J. (1968). Introduction to physical hydrology. Methuen publishers, London.

[3] Kumura, N. (2008). Application of Participatory G.I.S. for Rural Community Development and Local Level Spatial Planning System in Sri Lanka. Sri Lanka Rural Development Seminar.

[4] Zhilin Li, Qing Zhu, Christppher Gold, (2004) Digital Terrain Modeling: Principles and Methodology. CRC Press, Washington,DC.

[5] Musa, A. A. (2001). Application of GIS in planning field. A paper presented at the Department of Regional Planning, Modibbo Adama University of Technology, Yola - Nigeria.

[6] Ndukwe, O. (2001). Cadastral Database: An Essential Component of the Fundamental Datasets of a National Geospatial Data Infrastructure. Proceedings of Technical Session of the $37^{\text {th }}$ Annual General Meeting and Conference at Owerri pp. 19-24.

[7] Ward, R. C. (1978). Flood focal problems in Geography. A Geographic perspective. Mc. Millan press Limited London. 